\title{
Can universities play an active role in fostering entrepreneurship in emerging ecosystems? A case study of the University of São Paulo
}

\author{
Artur Tavares Vilas Boas Ribeiro* \\ Cidade Universitária, \\ 908-FEA, 1-Sala B 114, \\ São Paulo, 05508-900, Brazil \\ and \\ Faculdade de Economia e Administração, \\ Núcleo de Política e Gestão Tecnológica, \\ Universidade de São Paulo, Brazil \\ Email: Arturvb@usp.br \\ *Corresponding author
}

\section{Eduardo de Senzi Zancul}

Departamento de Engenharia de Produção, Escola Politécnica,

Universidade de São Paulo, Brazil

Email: ezancul@usp.br

\section{Justin Hugo Axel-Berg and Guilherme Ary Plonski}

Faculdade de Economia e Administração, Núcleo de Política e Gestão Tecnológica, Universidade de São Paulo, Brazil

Email: justin.axelberg@usp.br

Email: plonski2@usp.br

\begin{abstract}
The present study aims to identify patterns and roles that can be played by research universities in emerging entrepreneurship ecosystems. Its methodology is based on a case study of the University of São Paulo, analysing three startups born inside the university and the characteristics of its development processes. As a conclusion, we identify strategies to deal with bottlenecks and enhancers of an emerging entrepreneurship ecosystem, as well as patterns on how a university can stimulate entrepreneurship in a context of regional constraints - such as: 1) building interfaces between academic environments; 2) applying processes such as customer development using university capabilities; 3) empowering grassroots movements for entrepreneurship.
\end{abstract}

Keywords: entrepreneurship; entrepreneurship ecosystems; entrepreneurial universities; startups; venture creation; university; third mission; technology development; new business; economic development. 
Reference to this paper should be made as follows: Ribeiro, A.T.V.B., Zancul, E.D.S., Axel-Berg, J.H. and Plonski, G.A. (2018) 'Can universities play an active role in fostering entrepreneurship in emerging ecosystems? A case study of the University of São Paulo', Int. J. Innovation and Regional Development, Vol. 8, No. 1, pp.1-22.

Biographical notes: Artur Tavares Vilas Boas Ribeiro is a PhD student at the School of Economics and Administration and Accounting at the University of São Paulo (FEA/USP). He is an Administrator and earned his MSc in Entrepreneurship and Innovation from the University of São Paulo. He works with Startup Development at the USP, being the coordinator of USP Entrepreneurship Club and researcher at the Center of Technological Research and Management (PGT/USP). He is also, at USP, Assistant Monitor of entrepreneurship undergraduate courses at the Polytechnic School and Instructor of the undergraduate course Innovation and Entrepreneurship in Healthcare at the Faculty of Medicine.

Eduardo de Senzi Zancul has been an Assistant Professor at the Department of Production Engineering of the Polytechnic School at the University of São Paulo (POLI-USP) since 2009. He is a Mechanical Engineer and earned his $\mathrm{MSc}$ and $\mathrm{PhD}$ in Industrial Engineering from the University of Sao Paulo. Before joining USP, he was a Project Manager at the Bain and Company and a Research Assistant at the RWTH Aachen University in Germany. At the POLI-USP, $\mathrm{He}$ is the co-Founder and one of the coordinators of INOVALAB@POLI. His main research interests include design innovation, advanced manufacturing, and engineering education, focusing on design education.

Justin Hugo Axel-Berg is a researcher at the Institute of International Relations from the University of São Paulo on higher education governance and public policy, performance and research metrics, with a specific interest in metrics of social and economic impact. He is a member of the Centre for Higher Education Research, at the University of São Paulo, and the Centre for Technological Research and Management. He is a member of the International Triple Helix Association, participating in the Global Entrepreneurial University Metrics initiative. He received his Master's from the Institute of International Relations at the University of São Paulo, Bachelor's in Philosophy from the University of Sussex and Philosophy and Bioethics from the Monash University.

Guilherme Ary Plonski received his Master's and Doctorate in Production Engineering at the Polytechnic School at the USP (POLI-USP) and Fullbright post-doctorate from the Rensselaer Polytechnic Institute (RPI, United States). $\mathrm{He}$ is a Full Professor of the Department of Administration at the School of Economics and Administration and Accounting (FEA/USP) and Associate Professor at the Department of Production Engineering at the Polytechnic School at USP (POLI-USP). He is the Vice Director of IEA - Institute of Advanced Studies of USP and Scientific Coordinator of the Center of Technological Research and Management (PGT/USP). 


\section{Introduction}

The main challenges in promoting the joint action of agents for new business creation are to identify which efforts are most suitable for a given context, which agents should start initiatives and how to develop concerted action in order to optimise the development of entrepreneurship ecosystems in a healthy and efficient way.

The role of universities in entrepreneurship ecosystems is a key piece; historically, they are the fundamental bases of the triple-helix relationship, and its process of transformation and sustainability to promote the creation of new businesses. In Brazil, attention has been recently given to the role of higher education in promoting entrepreneurship and innovation, but because of the national history of late presence of universities (the earliest ones were created less than a century ago) many issues that are still being tackled generate impediments - ranging from structural inadequacies to mindset in higher education against fostering entrepreneurship.

Assuming that universities co-evolve with their ecosystems, and may have their role optimised or repressed (as well as being able to influence the environment they are inserted), this study is motivated by the search for understanding of how universities can play a vital role in supplying natural limitations in developing regions. We hope, therefore, to answer the following question: in a rapidly growing entrepreneurship environment, the city of São Paulo - the main focus of this paper as it is the main metropolis of the country - what concrete actions can a university take in order to assume an active role in fostering entrepreneurship in an emerging ecosystem?

Theoretical foundation is outlined in studies on the entrepreneurship ecosystems and the relationship with maturity of the ecosystem to the role of the university in one specific ecosystem: Waterloo (Canada). Three portraits on the role of the University of São Paulo (USP) in supporting the creation of new technology-based businesses are then outlined: mvisia; lean survey; dev technologies.

Theoretical foundation is applied to analyse the role of the USP in supporting the creation of new technology-based businesses.

\subsection{Goal}

The aim of this paper is to identify patterns and roles that can be played by a university in the entrepreneurship ecosystem of an emerging economy.

\subsection{Research question}

What concrete actions can a university take in order to assume an active role in fostering entrepreneurship in an emerging ecosystem?

\subsection{Methodology}

The methodology adopted in this paper is a case study about the USP and the strategic actions to stimulate the entrepreneurial activity in the university environment. Data sources were secondary sources of information and participant observation. The research followed four steps: 
1 Literature review and secondary data gathering - stage of research contextualisation, definition of a research question and secondary data collection about the USP and its elements. The secondary sources used were institution's official data.

2 Identification of students new venture portraits to elucidate the study-for a better understanding of USP specific actions on fostering entrepreneurship, this paper proposed the presentation of three histories of new venture creation within the university that highlight and detail the university actions and strategies, being considered a very rich source of qualitative data for the study.

3 Portraits data gathering - data gathering of three distinguished situations of company creation in USP: mvisia, lean survey and dev technologies. The data collection was constructed based on the ethnographic method of participant observation (detailed below).

4 Data analysis - the data compilation was carried out in three phases. The first one being an initial compilation, the second phase a presentation of the compiled material to the entrepreneurs portrayed for review and improvement, and a third phase with a final treatment involving two researchers external to the field research, based on the strategy in multiple research teams (detailed below) for case studies research (Eisenhardt, 1989).

\subsubsection{Method details}

Two elements of the chosen method bring the need for greater detail: participant observation and the use of multiple research teams. Participant observation is a method that has roots in ethnographic research that seeks to avoid the biases of interviews or other approaches by bringing the researcher to the field of study and placing it as an observer without generating interference and only recording their perceptions about the environment (Mack et al., 2005).

In the present case, two researchers brought their perceptions from the participation, during a period of more than a year, in the environments in which the three businesses portrayed were born. The richness of this method is characterised by collecting, from the point of view of specialists, the process of evolution and the elements related to greater depth and criticality, in addition to better access to the data. Such a choice is reinforced by Johnstone (2007) in the book Handbook of Qualitative Research Methods in Entrepreneurship
"An insider (complete participant) studying an entrepreneurial venture would have the advantage of beginning with a rich knowledge of the protagonists, the background and history of the venture, its culture and the social situation. Insider participants are also likely to have personal experiences and attributes that will help them gain acceptance and access." (Johnstone, 2007)

Thus, two researchers were responsible for, during months of monitoring the development of the business in a complete participant mode, collecting the data related to the three businesses portrayed. The annotations were made separately to bring greater richness of data by differences in viewpoints. After the data were compiled, the first results were presented to the entrepreneurs, who brought improvements, considerations and new insights into their stories. 
Figure 1 Research procedures and method (see online version for colours)

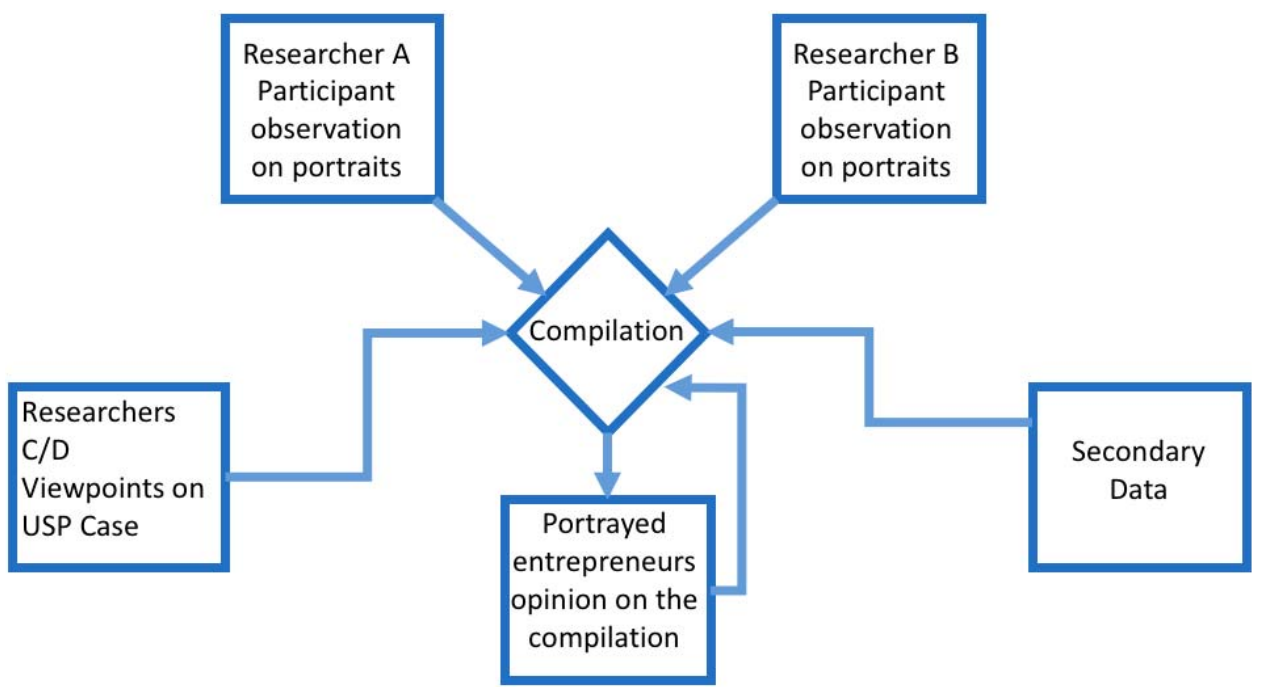

For the multiple research teams, this strategy was based on Eisenhardt's (1989) structure for case studies research. According to the author, using multiple researchers brings greater wealth in the data by

1 enriching the creative potential of the study with complementary insights

2 increasing the confidence in the findings through the convergence of observations

The author thus advances to the strategy of creating multiple research teams, with researchers participating of some field work and others not participating, in order to bring different points of view
"The rationale behind this tactic is that investigators who have not met the informants and have not become immersed in case details may bring a very different and possibly more objective eye to the evidence." (Eisenhardt, 1989)

In the present study, two researchers acted as participant observers raising data on the three portraits and two other researchers acted as specialists who brought their more in-depth contributions on the case of the USP and perceptions about emerging patterns in the observations (Figure 1).

\section{Literature review}

This literature review intends to illustrate the concept of maturity in entrepreneurial ecosystems, while highlighting the fundamental components required, before demonstrating the role universities can play in fostering entrepreneurship ecosystems. It finally shows a gap in the literature for more specific actions a university can make in ecosystems in emerging economies. 


\subsection{Entrepreneurship ecosystems and maturity stages}

Like world-class research universities, entrepreneurial ecosystems are fundamental to the creation of knowledge based economies and societies, and therefore the race to create both has gathered huge pace over the past two decades, with regions and governments the world over looking to replicate the success of the large US institutions and the ecosystems that often sprung up around them. Among the huge sums of money spent in, among others, Russia, China, Singapore and Saudi Arabia to create a high ranking university (Hazelkorn, 2015) and a world class entrepreneurial ecosystem, there has been a growing realisation that infrastructure investment alone is not sufficient to build an ecosystem. A (successful) entrepreneurial ecosystem is an arrangement of actors and conditions working collaboratively to foster high level entrepreneurial activity in a particular region (Regele and Neck, 2012; Nyman, 2015; Isenberg, 2011). Regele and Neck (2012) agree that the conditions for high level entrepreneurial activity covers topics like financial aid, public policies that foster technology transfer, legal and regulatory maturity, among others.

As complex networks of actors, ecosystems depend upon this physical and regulatory infrastructure, but pass through phases of maturing based principally on interaction and activity. Because of this, top-down approaches to ecosystem development have tended not to be as successful as those that have grown organically, bottom-up. The university plays a vital role in steering and stimulating contact and interaction between industry and university, acting as a coordinator and facilitator in a way that public policy and financial incentives alone have not proven as effective in generating (Balzer and Askonas, 2016).

Mason and Brown (2013) identify four common aspects to be identified as targets (recipients) for policymaking within a given ecosystem: entrepreneurial actors, entrepreneurial resource providers, entrepreneurial connectors and entrepreneurial orientators, although along with Feld (2012), they disagree that the university should be the site of this public policy because of the relatively low number of high growth companies they produce, along with the paucity of entrepreneurial education and stifling intellectual property regimes. For most authors however, and especially for those in less established ecosystems, the university provides a vital hub around which an ecosystem is oriented, bridging gaps between sectors (Chakrabarti and Rice, 2003), providing support networks, financing, facilities and most importantly of all, a concentration of highly skilled labour (Isenberg, 2011). Therefore, with some notable exceptions where the ecosystem is already reasonably mature and coordinated, and there is already a high concentration of skilled labour, such as in Denmark, the university is not necessarily the centre of the ecosystem.

With all the increased effort to bring the concept of entrepreneurship ecosystems to public policy and the agenda of private actors, it has also become necessary to present ways of doing horizontal analysis (evolution over time) and vertical analysis (comparing with other ecosystems), in addition to having a static snapshot. This need comes from a natural conclusion; ecosystems are distinct in different regions and have evolutionary (and involutionary) potential over time (Bell-Masterson and Stangler, 2015). Building the conditions for an entrepreneurial ecosystem is complicated. Several studies have emerged from this need; among them we list some references used in this article:

- Global Entrepreneurship Index 2016 (Ács et al., 2016).

- Global Entrepreneurship Monitor 2014 Global Report (Singer et al., 2015). 
- Entrepreneurial Ecosystems Around the Globe and Company Growth Dynamics Report (Foster et al., 2013).

- The Global Startup Ecosystem Ranking (Compass.co, 2015b).

- Measuring an Entrepreneurial Ecosystem (Bell-Masterson and Stangler, 2015).

It is not the purpose of this article delve into metrics and ecosystem measurement models. The important point here is to highlight the fact that there are large maturity differences between ecosystems (Cukier et al., 2015). This understanding can avoid confusion and dangers involved in the search for replicate role models instead of analyse its origin and development, as already pointed out by Etzkowitz (2013). While measurements of performance (outputs and processes) such as rankings can be a useful guide as to the level of activity of a given ecosystem, a better understanding of enabling aspects (inputs, intermediate processes and environmental factors) is needed in order to turn these into useful management tools (Rauhvargers, 2011).

The evolutionary and co-evolutionary potential of ecosystems has been well documented, Leydesdorff and Deakin (2011) suggests that over time, environments evolve and adapt in reaction and symbiosis with one another, communication networks densify and the level of entrepreneurial output increases. It is the role of the university to provide the fertile grounds for this to happen. This means that while infrastructure building is undoubtedly an important stimulation to more development, it is the human capital that develops the ecosystem (Harrington, 2017).

\subsection{The relationship between universities and entrepreneurship ecosystems maturity}

As the focus of this paper is an emergent ecosystem, the central aspect of its development is the intensification of communication and links between universities and industry in the development of entrepreneurial culture.

In his study of emerging ecosystems in the USA, Harrington (2017) places the key aspect of ecosystem growth as entrepreneur development as outside of mere entrepreneurial education in universities. In this, he highlights the importance of connectivity; the range and density of interaction between actors, the amount of fluidity between spheres and diversity of activity. It is this aspect, rather than principally regulatory environments or funding environments that he identifies as the determining factor in an ecosystem reaching maturity, through the development of entrepreneurial societies and clubs, in the role of mentoring and interfacing opportunities.

Wong and Wang (2004) surveyed the entrepreneurial intentions of Singaporean students, and found that like Brazil (Endeavor, 2012), the level of interest was extremely high, but the level of expertise and business knowledge was not sufficient to leverage entrepreneurialism. Wong et al. (2007) further supplemented this finding the noticeable change that the National University of Singapore underwent between these papers in inculcating entrepreneurial culture into curricula, implementation of conserted internationalisation efforts, and a change of stance from supplier of human capital and knowledge to being an agent of commercialisation itself. However, NUS's output was at that point still relatively low, pointing to the time many of these changes take to have measurable effects on an ecosystem. In this case the university played a vital role in developing entrepreneurial capabilities of students. 
Uvarov and Perevodchikov (2012) identify cultural factors as the largest barriers to success, and prescribe governmental intervention as the key factor in reverting this scenario. Balzer and Askonas (2016) compared this Russian approach with the Chinese efforts, and found that China had been much more effective in instituting entrepreneurial systems allowing fluid, bottom up structures based within universities, while Russia has preferred to maintain a government-driven, top-down model. Khan (2013) similarly points to the lack of interaction and communication in the Saudi Arabian ecosystem, while universities take a relatively less dominant role in the ecosystem when compared to the state.

In contrast, Israel's ecosystem is one of the most vibrant and active on earth. In large part this is down to the maturity and flexibility of its venture capital infrastructure and public funding, a culture in which risk-taking is actively encouraged and international networks are fostered and promoted heavily. In this ecosystem the cultural barriers between universities and industry are not present, and the role of Israel's main universities is catalysed within the ecosystem. The role of academic institutions in the country is a key factor in the ecosystem's development, increasing national productivity, advancing R\&D (civil and military), developing the local industry and generating new technologies (Avidor, 2011). The results, according to the state of Israel Ministry of Economy (Israel, 2015), are evident: annually, Israeli technology transfer companies generate over US \$350 million in royalties, about 150 new technologies are licensed from universities and research institutions, 15 new academic-based companies spun out and Israeli technology transfer companies are ranked among the top of the world in terms of revenues.

Paying more attention to specific roles, universities can play a fundamental role in entrepreneurship ecosystems. Gathering some recent studies and rankings about the role of university in entrepreneurship ecosystem, four major categories were identified: entrepreneurship education; talent formation; cultural influence; technology generation.

Table 1 University-related elements in entrepreneurship ecosystem measurement studies

\begin{tabular}{ll}
\hline & University-related elements in ecosystem measurement studies \\
\hline Entrepreneurship & - Startup skills; business strategy (Ács et al., 2016). \\
education & - Entrepreneurship in universities; methodology knowledge (Cukier \\
& et al., 2015). \\
- Major universities playing a key role in idea-formation for new & companies; entrepreneur-specific training (Foster et al., 2013). \\
- Entrepreneurship education at post-secondary levels (Singer et al., & 2015). \\
- Staff training; educational level (Ács et al., 2016). \\
- Technical talent; major universities playing a key role in \\
providing graduates for new companies; available workforce with \\
university education (Foster et al., 2013). \\
- Talent quality (Compass.co, 2015b). \\
- Major universities promoting a culture of respect for \\
entrepreneurship (Foster et al., 2013). \\
- Technology transfer processes (Cukier et al., 2015). \\
- Spin-off rate (Bell-Masterson and Stangler, 2015). \\
\hline Technology generation
\end{tabular}


We can see from this table that there is a large degree of crossover between functions; entrepreneurial education has a role in changing the cultural outlook of a university, as it also does on technology generation, while technology generation mechanisms conversely give more incentive to entrepreneurship education program by producing successful cases and future mentors. Universities should take a holistic approach to entrepreneurial strategy (Spinosa et al., 2015).

Using a maturity view is an important guide based on the premise that universities, the central unit of analysis of this study, co-evolve with their societal environments (Nyman, 2015). They therefore reflect characteristics, collaborate with its progress, are affected by limitations and - the most important aspect in our case - they develop their own mechanisms to address regional deficiencies (Davey et al., 2016).

\subsubsection{Ecosystem-Waterloo, Canada}

The Waterloo region is recognised for the potential of its ecosystem in information communication technology (ICT) (Nelles et al., 2005; Bramwell and Wolfe, 2005) and has a variety of data in its favour, as pointed out by the Waterloo Region Economic Development Corporation (Corporation, 2016):

1 over 1,000 technology firms (including Canada's largest software, hardware, e-learning and satellite companies)

2 numbers of patents granted exceeding ten times the national average

3 global recognition of the mass of talent in technology, with 65,000 post-secondary students in three well-established institutions - University of Waterloo (recognised as the highest concentration of computer science and mathematics students in the world), Wilfrid Laurier University (focused on business education and MBA) and Conestoga College Institute of Technology and Advanced Learning (renowned School of Engineering and IT).

In addition to the intellectual potential of the region, the University of Waterloo is distinguished by a strategy related to intellectual property, the 'inventor's-own intellectual property' that stays in the core of the innovation culture of the university. For Burns (2013), this generates positive economic developments thanks to more attraction and entrepreneurial, industry-focused faculty, more industry-friendly IP agreements and a greater sense of freedom for the commercialisation of inventions.

Although it has a promising environment, according to the study 'the David vs. Goliath of startup ecosystems' (Compass.co, 2015a), the small Canadian city of about half a million inhabitants still has limitations that prevent its exponential growth as an ecosystem. The study shows many positive characteristics of the ecosystem: a diverse environment, positive culture towards entrepreneurship, good practices of entrepreneurship education such as cooperation programs where students go through a series of internships at leading companies around the world, and the communitech, a public-led innovation centre that offers structure for acceleration, startup residence, incubator space and mentorship programs. However, some aspects of funding are very harmful - the conservative mindset of local investors who avoid high risk investments, a lack of experienced technology investors (elapsing in low valuations) and the geographical distance of more established funds. In addition, a limited market ambition is still present in Waterloo entrepreneurs, highlighted by the lack of marketing and sales 
talent, global focus and aggressive growth drive. These negative aspects influence the whole Waterloo ecosystem, imposing barriers to its growth and its efforts to create an attractive and promising environment for entrepreneurship. As we pointed out, elements of ecosystems co-evolve, and are often limited by aspects that public policies cannot directly control or foresee.

\subsection{The practical role of the university in entrepreneurship ecosystems}

The literature shows a diversity of approaches to resolving an often similar set of issues, however there is a gap in the literature proposing concrete actions for universities in these ecosystems, as there are for emerging ecosystems in the USA (Harrington, 2017; Tornatzky and Rideout, 2014b). Although a presentation of a general context is useful, Guerrero et al. (2015) reinforce the need to see more specific contributions of institutions, such as actions, externalities and institutional leadership. Naqshbandi and Kaur (2014) in their analysis of managerial ties in a Malaysian ecosystem point to the importance of observing the challenges of building links between industry and universities in encouraging entrepreneurship and innovation. The authors point out that although there is a high probability that companies will consider universities as an external source of knowledge to access, there is a challenge of reaching the right person in the first place due to the complexity of the institutions, which reduces the possibilities of technology transfer.

Rasmussen and Wright (2015) bring a framework based on entrepreneurial competences and university action on them. For the authors, there are three key competences to be developed by academic entrepreneurs and strategies for their development in the university:

1 Opportunity development competency - ability to discover and exploit opportunities from research, turning them into business concepts. According to the study, it is a competence linked to the level of entrepreneurs-industry interaction and the level of alternatives exploration of an opportunity.

University roles: provide access to industry; involve external industry and investors; foster industrial connections.

2 Championing competency - ability to connect with the business purpose in a deeper way and to convince and inspire other agents to collaborate with its development. In addition to being a feature dependent on personal motivations, the authors point out the impact of university culture and teachers' beliefs in creating a stimulating environment for entrepreneurship.

University roles: foster connections for founding teams; allow (and encourage) spin-off creation.

3 Resource acquisition competency - ability to arrange internal and external resources to exploit the business opportunity.

University roles: gain access to external funding; offer non-monetary resources; help new ventures obtain resources; network with industry and investors.

Drawing on future studies, Guerrero et al. (2015) and Clark (2004) bring important themes to be explored, such as student engagement in the entrepreneurial university 
mission, the social impact of entrepreneurial universities, and university strategies for new economic contexts. When planning activities to be implanted into universities, Tornatzky and Rideout (2014a) discuss the key elements to successful planning for a university feeding an entrepreneurial ecosystem; fungibility and adaptability. It should be possible to move parts of a university policy to other contexts, to learn from them and to adapt to local needs and capacities. This means that while universities may have relatively similar goals for their role in an innovation ecosystem, they should be aware of their constraints and unique position within it.

Corroborating the argument put forward in this literature review, Guerrero et al. (2016) point to a gap in the literature in terms of strategies and concrete actions that can be taken by universities in fostering entrepreneurship in turbulent economic conditions. Based upon this, this study aims to answer the following question: what concrete actions can a university take in order to assume an active role in fostering entrepreneurship in an emerging ecosystem?

\section{Case study - city of São Paulo ecosystem and University of São Paulo, Brazil}

\subsection{The Brazilian context and the role of universities}

The Brazilian context has a number of peculiarities that should be highlighted. As shown by Zouain and Plonski (2015), the country is distinguished by its proportions, both in terms of size and population, and a history of rapid urbanisation, which generated internal migration of unskilled peasants to urban areas - currently about $85 \%$ of the population of approximately 200 million people live in urban areas. According to the authors, and supplemented by Rolim et al. (2014), this history has generated some structural problems for the nation, such as income concentration, regional inequalities, low productivity in some sectors, cultural and environmental disturbances, difficulties in job opportunities, mobility constraints and imbalanced quality in its educational system.

This macro context has direct and specific consequences on the entrepreneurship movement in Brazil. According to research done by Endeavor (2015), although three out of four Brazilians choose entrepreneurship as a career choice, only $4 \%$ have an enterprise capable of employing other people. This situation is related, according to the study, to the difficulty of opening new firms, taxation structure, problems in team building and obstacles in finding clients. For this study, the ecosystem of the city of São Paulo will be given exclusive attention, which is notable for being the leading economy of the country, and which directly connects to the university where the case emerged; the USP.

When it comes to higher education, the Brazilian context runs in parallel with the development of the country, especially since the major research universities are public and suffer from structural impediments and difficulties in targeting academic foundation for fostering entrepreneurship and healthy relationships with industry (Rolim et al., 2014). As pointed out by Mota and Scott (2014), Brazil has an improving performance profile in higher education:

1 leading Latin American HE rankings

2 having increased the number of private for profit institutions in the scenario 
3 encouraging international involvement with programs like science without borders

4 growing number of scientific publications to become the 13th largest publisher of journal papers in the world.

But despite the growth in scientific activity, the authors points that the patent production number remains extremely low, creating a need to "go beyond the production of scientific knowledge to move into the area of creating scientific products".

In fostering entrepreneurship, a recent study by Endeavor (2012) points out that few students interested in entrepreneurship receive adequate training in Brazilian universities, with inadequate efforts by institutions in the development of programs related to the topic.

\subsection{The city of São Paulo entrepreneurship ecosystem}

The city of São Paulo is the largest economic centre in Brazil, and also the 10th richest city in the world - with more than $60 \%$ of national venture capital and private equity invested in the city, as well as a state government that invests almost $4.5 \%$ of its budget in fostering innovation (Endeavor, 2015). As a result of the rapid urbanisation migration processes noted above, many national problems are intensified in its main metropolis, one of them reflects in the numbers linked to higher education - although many of the best universities in the country are found in the region, only $24 \%$ of the population reaches higher education. This, coupled with the demand for professionals coming from the high concentration of multinationals and large enterprises, makes the skilled labour force scarce, creating difficulties for new companies hiring and accessing the talented people needed for growth (Endeavor, 2015).

As a startup environment, the city draws attention: the report of Compass.co (2015b) points out the startup ecosystem of São Paulo as the third fastest growing in the world, the city being home to about 1,500-2,700 active startups. The venture capital activity has been noted for its intense movement, including silicon valley funds settling in the city - however, as a recent development, new businesses also have considerable difficulty in attracting first investment. The report also notes that for new firms, national problems linked to high costs, bureaucracy and burdensome transportation systems hinder the processes of firm creation in the city.

\subsection{University of São Paulo}

The USP is a public research university founded in 1934 and is known for being the most prominent universities in Latin America, consistently ranking in first place in all regional and first among Latin American institutions in international university rankings, and also ranked first in the recent entrepreneurial universities national ranking. The university has several campuses in the state of São Paulo, four in the capital and seven distributed in other cities (Bauru, Lorena, Piracicaba, Pirassununga, Ribeirão Preto and São Carlos), with approximately 100,000 enrolled students, and a structure covering 48 schools and advanced research institutes, four hospitals and supporting services, 46 libraries and four museums (USP, 2015). In terms of entrepreneurialism, the USP displays many characteristics typical of Brazilian higher education: cultural barriers for entrepreneurialism, a mentality strictly focused on academic production and bureaucratic complexity that inhibits the creation of businesses. However, it does have a long history 
of producing dozens of academic spin-offs every year (a census is being currently undertaken to identify these firms), it has a wide variety of support mechanisms [incubators, technology transfer office (TTO), student-led movements, laboratories focused on the production of firms, among others], as well as having undergone an important process of transformation in its approach to third mission activities. For this study, we will focus on two key agents of the university's approach, and three university startup development processes.

\subsection{InovaLab@Poli}

InovaLab@POLI was established in 2012 as an innovation lab focused on providing undergraduate and graduate students with the resources needed to innovate and potentially start new businesses. The motivation to create InovaLab@POLI appeared in 2011. Even though the USP provided relevant and well-equipped teaching and research labs, there was a perception of a lack of project and prototyping spaces for students to freely work on longer-term projects of their own interest. Such projects ranged from course work, to final dissertation and their own initiatives. Currently, InovaLab@POLI facilities are located in the School of Engineering, and the premises are open to the whole campus community. The lab offers four different and complementary physical spaces: a project room, equipped with office space, video conferencing and low-cost 3D-printing; mechanical shop-floor; an electronics workshop; an international project room, to host longer-term teams with international students that need more fixed space for targeted efforts. InovaLab@POLI also adapted a traditional classroom into a flexible teaching space for classes involving group work. All spaces are open-access and no permission is required to use lab premises and equipment. Certain equipment may require specific training and safety procedures. The main references for setting up InovaLab@POLI came from Stanford's product realisation lab and the finish Aalto University design factory initiative. Currently, frequent student usage includes undergraduate final dissertation, which in some cases leads to startup creation. InovaLab@POLI hosts USP Entrepreneurship Club (UEC). The integration of both institutions in the same space facilitates the combination of technological innovation and entrepreneurship interests and knowledge.

\subsection{USP entrepreneurship club}

The UEC is a student-led organisation that emerged in 2012 in an autonomous and spontaneous grassroots way from the motivation of student entrepreneurs looking to share experiences with colleagues. This movement arose as the result of the perception that the exchanges could expand undergraduate support and experience interested in entrepreneurship, support that at the time was perceived as a gap that the USP did not meet. As the organisation matured, three main pillars were identified for full development; inspiration, empowerment and connection. There was also a partnership establishing the organisation within the InovaLab@POLI environments in order to optimise synergies.

Inspiration focuses on lectures, videos, events, lunches with entrepreneurs, environments with high concentration of startups and evangelisation through success stories spread on social networks with a reach of approximately 50,000 people. For empowerment, there are design events (as startup weekends), courses, support for 
undergraduate classes with content and active participation, and a concentrated program to transform ideas into startups. In connection are efforts to leverage start-ups, such as:

1 bridges with investment funds, support and referral to screening programs

2 connections with accelerators and incubators

3 support in projects that provide financial resources without equity participation

4 actions that encourage networking

5 a platform to connect graduate students with internships in the UEC network of companies and other smaller specific actions.

As a result, many of the top startups in the country, led by students from USP, was supported in some way by the club, whose valuation reaches hundreds of millions of dollars, many passing linearly through the inspiration-empowerment-connection cycle, and, after relative success, returning to the university to restart the cycle as agents of inspiration, empowerment or connection, thereby generating a positive feedback loop of entrepreneurship in the university. Three situations of startups supported by the club are presented here - mvisia, lean survey and dev technologies.

\subsection{Mvisia: mechatronics applied to agribusiness}

Mvisia began in an entrepreneurship class focused on experiential learning, multi disciplinarity and connection between an engineering school and a business school (Polytechnic School of the USP and Getúlio Vargas Foundation), a group of students identified a demand to apply their skills in mechatronics and mechanics to create machines capable of optimising the organisation, selection and planting of seedlings for the eucalyptus market, which is worth $\mathrm{R} \$ 300$ million per year in Brazil.

The project development matured in the course, and the machine was developed as an undergraduate final project at the Mechatronics Department of the School of Engineering at USP. Teachers and researchers from the Mechatronics Department had developed a program in partnership with the UEC to encourage 'entrepreneurial implementation' of undergraduate final projects, fostering transformation into technology-based start-ups. The program, lasting six months, takes place in parallel with the development of the technical project and makes use of startup acceleration mechanisms, including initial funding of about US\$5,000; equivalent to zero stage funding in Brazil, without equity for the development of a functional prototype. The group signed up to participate and was selected for the program, which was divided into three major foundations:

1 Live workshops - occurring at the beginning and end of the program, involving lectures from specialists, contacting relevant market people, courses and specific dynamics for project refinement.

2 Monitoring and mentoring - similar to an acceleration program, the projects developed over the six months with delivery schedules and intensive mentoring by business specialists who 'patronised' teams and gave weekly support and directions to business evolution.

3 Demo day - the program ended in a demo day at the São Paulo State Technological Park with an investment fair and exposure to various investors and entrepreneurs. 
Through this connection, the program aimed to encourage continuity and support offered for such projects.

At the end of the program, mvisia became a company and advanced the relationship with prospects made and other market opportunities. Operations were initially established in InovaLab@POLI. During the entrepreneurship program, founders were directed and received intensive support to participate in an entrepreneurial competition, whose prize was US \$25,000 - equivalent of a seed funding round in Brazil.

\subsection{Lean survey: market research based on crowd sourcing}

The company lean survey was born in 2014 as a result of the UEC in an entrepreneurship discipline of the engineering school, including placement in InovaLab@POLI to devote full time to the project, under the supervision of a coordinator of the Laboratory and professor at the School of Engineering. This project was one of the first experiences of the UEC startup lab, a startup development program that seeks to apply some methodologies based on the concept of costumer discovery (Blank, 2013) in a four-step process:

1 Immersion: understanding the market, trend study, potential competitors and interviewing processes. This phase encourages students to build a customer oriented approach and better understand the market. It is a moment of connecting with experts, potential customers and influencers to perform dozens of interviews focused on user issues. Specific contents are costumer discovery (Blank, 2013) and do things that do not scale (Graham, 2013). Lean survey profoundly changed the value proposition of the business, a moment identified by the founders as game-changing. The entrepreneurs conducted more than 60 interviews with managers from large companies and identified other demands and potential customer expectations, which directed the product structure focused on bringing technology to a highly outdated manual market in the Brazilian market research scene.

2 Validation: entrepreneurs are directed to design their business model and map the fundamental assumptions. Minimal actions are thought focusing on ensuring validation and learning more about the product - a process known as minimum viable product development (lean startup approach). The book Lean Startup (Ries, 2011) and the text 'the minimum viable product is not a product, it is a process' (Birkman, 2016) are used. Lean survey sought to implement small market research tests in the university environment with some directions from the UEC and other early adopters interested, such as the administration of the School of Engineering at USP.

3 Market fine tuning: project ripening through connections and insertion of the product. Events and team building activities building are made, and the UEC offer support participation in entrepreneurship competitions that can guarantee significant financial and market results, as well as connections with more mature entrepreneurs from UEC network for strategic direction that nascent businesses demand. For lean survey, this moment was important to find a partner on the part of development and technology - something that occurred at an event organised by the Free Open Source Software Competence Club (Department of Computer Sciences from Institute of 
Mathematics and Statistics of USP), next to the UEC, in order to connect developers with entrepreneurs.

4 Maturing from the ecosystem: the last phase of the startup lab focuses on stimulating more mature connections, such as with investors, major customers, incubators, public policies etc. The maturing phase was important for lean survey in the process of connecting to large companies and professional operation with exponentially growing cash flow. The UEC support occurred in organising a group of entrepreneurs for the rental of a neighbouring space to the University of São Paulo who now works as a co-working hotbed for USP startups, support relations with lean survey biggest first customer (large technology company belonging to the UEC network), connection with an international venture capital fund and access to important vehicles of the Brazilian media.

Passing through the UEC startup lab, establishing its early days operation in InovaLab@POLI (being guided by a professor coordinator of the space) and counting on the great commitment/talent from the entrepreneurs, lean survey trod a journey that began as an idea in the classroom and became a startup whose market value in the first year reached the million mark.

\subsection{DEV technologies: internet of things and automation of production processes}

The company dev technologies, which develops equipment for the internet of things and automation of production processes, was born in 2012 in the USP with two students of electrical engineering (computer engineering and electronic systems) developing hardware for automation research laboratories of the university - a project that has expanded to other universities. Officially founded in 2013, consisting of four founder engineers and based in technology, entrepreneurship and innovation centre, the technological incubator from the USP, has advanced the development of connected devices and migration to the IoT market. The first product was a power meter in a large project related to efficiency lamps. They began to receive support from one the of InovaLab@POLI coordinators for the implementation of a project for a financial public funding aid for the development of technology in businesses the state of São Paulo. This mechanism, the program for innovative research on small companies, offers amounts from close to a seed funding round, and even to a series A round in Brazil, with low counterparts and no stake in the company. It is one of the best mechanisms for purchasing equipment and services contracting for technology-based start-ups in the state of São Paulo.

With the financial aid raised through the public mechanism and a reduced cost structure through the establishment of operations on the Incubator, besides good relationship with university and government, DEV could grow and acquire other funding support mechanisms from National Council of Technological and Scientific Development, which ensured the hiring of researchers and scholarship holders to expand the operation. Currently, three years after the foundation, it employs nearly 20 people. The advances in the provision of services to the public sphere gave thanks to interfaces promoted by the USP, including ensuring the company's involvement in presenting their solutions to those responsible for the state of São Paulo, including the government itself, in 'pitch gov. São Paulo' program. 


\section{Discussions}

From the literature review and case study, we can identify some central aspects that both supplement and conflict with the theory. There are a number of similarities with the international cases presented. For example, both the USP and the University of Waterloo represent vanguard efforts in their respective ecosystems, and are limited by cultural constraints; a social barrier with regards to high-growth driven mindsets, risk aversion and a lack of global focus. There are also similarities between the vibrant structures of financing mechanisms, from either public or private sources in Israel and Brazil and their catalysing effect on the development of university startups geographically connected to them, and finally the role of student-led grassroots organisations in creating a vibrant atmosphere and transformative conditions in both the USP.

Concentrating on the analysis of the startup development processes in the USP, some lessons can be taken, especially with regards to the central theme of this study; the capactiy of a university to adapt to the limitations inherent in its ecosystem's stage of development. Table 1 organises these ecosystem characteristics and mechanisms used for each factor. This refers to the university in general, as individual functions are performed by a variety of actors; laboratories, student organisations and others.

Table 2 Maturity characteristics of São Paulo ecosystem and USP coping strategies

\begin{tabular}{|c|c|c|}
\hline \multicolumn{3}{|c|}{ Maturity characteristics of São Paulo ecosystem and USP coping strategies } \\
\hline \multicolumn{2}{|c|}{ Maturity characteristics } & Coping actions \\
\hline Bottleneck & $\begin{array}{l}\text { Lack of entrepreneurial } \\
\text { training (Endeavor, 2012) }\end{array}$ & $\begin{array}{l}\text { Entrepreneurship talks, courses and classes; } \\
\text { pre-accelerator programs; workshops; mentorship } \\
\text { programs. }\end{array}$ \\
\hline Bottleneck & $\begin{array}{l}\text { High costs for infra } \\
\text { (Compass.co, 2015b) }\end{array}$ & $\begin{array}{l}\text { Physical spaces or laboratories focused on } \\
\text { entrepreneurship and innovation support; } \\
\text { university technological incubator; partnerships } \\
\text { and relations of university with private players } \\
\text { (co-working spaces, accelerators and corporate } \\
\text { programs). }\end{array}$ \\
\hline Bottleneck & $\begin{array}{l}\text { Lack of early stage funding } \\
\text { (Compass.co, 2015b) }\end{array}$ & $\begin{array}{l}\text { Good relationship between university and private } \\
\text { sector to create entrepreneurship programs with } \\
\text { zero-stage funding (no equity); support of students } \\
\text { on entrepreneurship prizes and competitions. }\end{array}$ \\
\hline Bottleneck & $\begin{array}{l}\text { Public services bureaucracy } \\
\text { (Compass.co, 2015b) }\end{array}$ & $\begin{array}{l}\text { Direct support in public services processes; } \\
\text { teachers mentoring students with applications. }\end{array}$ \\
\hline Enhancer & $\begin{array}{l}\text { Rich VC and public } \\
\text { funding scene (Endeavor, } \\
2015 \text { ) }\end{array}$ & $\begin{array}{l}\text { University involved in VC screening processes; } \\
\text { direct connection between entrepreneurs and VC's; } \\
\text { demo days; good university-government } \\
\text { relationship for public funding; network effects. }\end{array}$ \\
\hline Bottleneck & $\begin{array}{l}\text { Difficult on finding clients } \\
\text { (Endeavor, 2015) }\end{array}$ & $\begin{array}{l}\text { University as an early adopter; pre-accelerator } \\
\text { programs; networking activities; university giving } \\
\text { the brand and directly advocating for first clients. }\end{array}$ \\
\hline Bottleneck & $\begin{array}{l}\text { Finding high skilled people } \\
\text { for team building } \\
\text { (Endeavor, 2015) }\end{array}$ & $\begin{array}{l}\text { Events focused on team building; formal platform } \\
\text { to connect students for internships; startup } \\
\text { weekends. }\end{array}$ \\
\hline
\end{tabular}


From the discussions outlined here and material brought to the study, some patterns can be identified which could be useful for replication in other ecosystems and universities, at any stage of ecosystem maturity. Such patterns can be organised as a short response on the strategies element of the question that orients the study: what concrete actions can a university take in order to assume an active role in fostering entrepreneurship in an emerging ecosystem?

a Building interfaces - it can be perceived that, because entrepreneurs have a wide range of demands for support in an ecosystem that the system itself does not provide, distinct movements emerge from inside the university. Once these movements are concentrated, the results are maximised and the evolution of entrepreneurs happens in a connected way. At the USP, the interface between practice and the network of contacts at the UEC inside the official maker space at the School of Engineering (InovaLab@POLI ) has been very productive in this sense, allowing the maturing of students as entrepreneurs and, at the same time, guaranteeing infrastructure and access to resources capable of growing and developing the business. Other interactions were observed throughout the history of these companies, such as participation in the university's incubator, other laboratories/departments, combined disciplines between the engineering school and a business school and government/university/industry relations. Systematic thought, in this case, was a huge differentiator, taking into account physical space, public stimulation mechanisms, specific people, university organisations and the network of contacts with established entrepreneurs.

b Thinking in customer development through the university structure - the processes of customer development, generally used during the startup acceleration phase, can have amplified effects when applied to the university context. In the case of the USP, this unfolds across a number of lines; the role of specialist professors at the moments of identification of market potential; the alumni network of entrepreneurs offering mentorship and being first clients; the openness of large companies to new enterprise as a result of being a project from the university; university laboratories being the first clients of high technology projects - all are characteristics of the technical deepness found specifically in the structure of the university's engineering school.

c Empowering grassroots movements to foster entrepreneurship - as recently published research shows, the process of transformation towards the third mission can occur in a number of different ways. One of them is through spontaneous and autonomous movements by members of the academic community (students, professors, researchers etc.). In USP's case we can see this pattern as a determinant, with the grassroots student-led movement UEC and also in initiatives of professors whose appearance is partly due to individual efforts to prioritise entrepreneurialism in their own departments and laboratories.

These strategies can present an interesting relation to the Rasmussen and Wright (2015) framework, in which: the construction of interfaces between laboratories and students (item a) amplifies the university culture and stimulates the championing competence; the customer development approach (item b) fosters the interaction with the market and the reflection on business alternatives, reinforcing the development in opportunity development competency; the grassroots movements (item c) brings new horizons for the 
student/alumni level and its role within the strategies and actions of an entrepreneurial university.

\section{Conclusions}

The aim of this paper is to identify potential strategies for universities inserted into ecosystems whose level of maturity is still not sufficiently advanced to leverage entrepreurialism in a clear and simple way. For this, we compared a case study of São Paulo to Waterloo in Canada in order to identify the role of universities at distinct ecosystem maturity levels and, from this, merge into the Brazilian context, whose recent urbanisation still presents constraints on the development of technology businesses, especially academic spin-offs.

The results of the study bring new references towards actions and strategies that can be performed by universities in a context of economic turmoil, with complex barriers hindering the development of new business. In addition, the results add elements to established models, such as the framework of Rasmussen and Wright (2015). Finally, there is the reinforcement of two new elements that are little discussed in academic entrepreneurship research: the figure of the entrepreneur as an undergraduate student or recently graduated (different from the classic figure of the entrepreneur as a researcher generating spin offs based on academic research); and the role of grassroots movements focused specifically on fostering entrepreneurship - the entrepreneurship clubs. These two elements represent new horizons for future studies and have been shown, in the case of the USP, key pieces in the composition of a vibrant entrepreneurship ecosystem.

After bringing the perception that ecosystems should be viewed in terms of their degree of maturity, it can be understood that the adaptation of a university also is affected by effects of these stages of maturity. It is therefore important to be aware of the mechanisms of transformation in operation. For the future, we must reflect on adaptation processes for universities in order to play an effective role in fostering entrepreneurship from the perspective of maturity models applied to the systems in which they are inserted.

\section{References}

Ács, Z.J., Szerb, L. and Autio, E. (2016) Global Entrepreneurship and Development Index 2015, p.1, Springer.

Avidor, J. (2011) Building an Innovation Economy: Public Policy Lessons from Israel, Northwestern Law \& Econ Research Paper, June, Nos. 11/18, p.1.

Balzer, H. and Askonas, J. (2016) 'The triple helix after communism: Russia and China compared', Triple Helix, Vol. 3, No. 1, p.1.

Bell-Masterson, J. and Strangler, D. (2015) 'Measuring an entrepreneurial ecosystem', Kauffman Foundation Research Series on City, Metro and Regional Entrepreneurship, March.

Blank, S. (2013) The Four Steps to the Epiphany: Successful Strategies for Products that Win, BookBaby.

Bramwell, A. and Wolfe, D.A. (2005) 'The entrepreneurial university of waterloo', Canadian Political Science Association Annual Conference. 
Birkman, Y.J. (2016) A Minimum Viable Product is not a Product, it's a Process [online] http://www.blog.ycombinator.com/minimum-viable-product-process/ (accessed 4 January 2017).

Burns, C.M. (2013) 'Pathway to innovation', Industrial Biotechnology, Vol. 9, No. 5, pp.258-259 [online] http://doi.org/10.1089/ind.2013.1593.

Chakrabarti, A. and Rice, M. (2003) Changing Roles of Universities in Developing Entrepreneurial Regions: the Case of Finland and the US, Industrial Performance Center, MIT IPC Working Paper IPC-03-003, September.

Clark, B.R. (2004) Sustaining Change in University, Open University Press.

Compass.co (2015a) 'Waterloo startup ecosystem report - the David vs. Goliath of startup ecosystems', The Startup Ecosystem Report Series.

Compass.co (2015b) 'The global ecosystem startup ranking 2015', The Startup Ecosystem Report Series.

Corporation, W.R.E.D. (2016) Quick Facts [online] http://www.waterlooedc.ca/en/why-investinwaterloo-region/Quick-Facts.asp (accessed 6 January 2017).

Cukier, D., Kon, F. and Krueger, N. (2015) Designing a Maturity Model for Software Startup Ecosystems [online] http://www.researchgate.net/publication/283352688_Designing_a_ Maturity_Model_for_Software_Startup_Ecosystems

Davey, T., Rossano, S. and van der Sijde, P. (2016) 'Does context matter in academic entrepreneurship? The role of barriers and drivers in the regional and national context', The Journal of Technology Transfer, Vol. 41, No. 6, pp.1457-1482.

Eisenhardt, K.M. (1989) 'Building theories from case study research', The Academy of Management Review, Vol. 14, No. 4, p.532-550.

Endeavor (2012) O Empreendedorismo nas Universidades Brasileiras [online] http://www.endeavor.org.br/o-empreendedorismo-nas-universidades (accessed 10 January 2017).

Endeavor (2015) Índice de Cidades Empreendedoras - Brasil 2015 [online] $\mathrm{http}: / / \mathrm{www}$.info.endeavor.org.br/ice2015 (accessed 10 January 2017).

Etzkowitz, H. (2013). 'StartX and the 'paradox of success': filling the gap in Stanford's entrepreneurial culture', Social Science Information, Vol. 52, No. 4, pp.605-627.

Feld, B (2012) Startup Communities: Building an Entrepreneurial Ecosystem in your City, Hoboken, NJ, Wiley.

Foster, G., Shimizu, C., Ciesinski, S., Davila, A., Hassan, S., Jia, N. and Morris, R. (2013) 'Entrepreneurial ecosystems around the globe and company growth dynamics', in World Economic Forum, Vol. 11.

Graham, P. (2013) Do Things that Don't Scale [online] http://www.paulgraham.com/ds.html (accessed 20 December 2016).

Guerrero, M., Cunningham, J.A. and Urbano, D. (2015) 'Economic impact of entrepreneurial universities' activities: an exploratory study of the United Kingdom', Research Policy, Vol. 44, No. 3, pp.748-764.

Guerrero, M., Urbano, D., Fayolle, A., Klofsten, M. and Mian, S. (2016) 'Entrepreneurial universities: emerging models in the new social and economic landscape', Small Business Economics, Vol. 47, No. 3, pp.551-563.

Harrington, K. (2017) Entrepreneurial Ecosystem Maturity and Momentum the Important Role of Entrepreneur Development Organizations and their Activities, Ewing Marion Kauffman Foundation [online] http://www.kauffman.org/what-we-do/research/2017/entrepreneurialecosystem-momentum-and-maturity (accessed 29 May 2017).

Hazelkorn, E. (2015) Rankings and the Reshaping of Higher Education: The Battle for World-Class Excellence, 2nd ed., Palgrave Macmillan, London. 
Khan, M.R. (2013) 'Mapping entrepreneurship ecosystem of Saudi Arabia', World Journal of Entrepreneurship, Management and Sustainable Development, Vol. 9, No. 1, pp.28-54, DOI: $10.1108 / 20425961311315700$.

Isenberg, D. (2011) The Entrepreneurship Ecosystem Strategy as a New Paradigm for Economic Policy: Principles for Cultivating Entrepreneurship, Presentation at the Institute of International and European Affairs.

Israel (2015) Israel Trade and Economic Office, Embassy of Israel - Geneva, Switzerland, Israeli Ministry of Economy and Industry - Foreign Trade Administration [online] http://www.itrade.gov.il/switzerland/ittn-2015-3rd-conference-of-the-israel-tech-transferorganization (accessed 20 December 2016).

Johnstone, B.A. (2007) 'Ethnographic methods in entrepreneurship research', in Neergaard, H. and Ulhøi, J.P. (Eds.): Handbook of Qualitative Research Methods in Entrepreneurship, Edward Elgar Publishing, Cheltenham/Northampton, MA.

Leydesdorff, L. and Deakin, M. (2011) 'The triple-helix model of smart cities: a neo-evolutionary perspective', Journal of Urban Technology, Vol. 18, No. 2, pp.53-63.

Mason, C. and Brown, R. (2013) 'Entrepreneurial ecosystems and growth oriented entrepreneurship background paper', OECD [online] http://www.oecd.org/cfe/leed/ Entrepreneurial-ecosystems.pdf (accessed 16 December 2016).

Naqshbandi, M. and Kaur, S. (2014) 'Do managerial ties support or stifle open innovation?', Industrial Management \& Data Systems, Vol. 114, No. 4, pp.652-675.

Nelles, J., Allison, B. and David, W. (2005) 'History, culture, and path dependency', in Global Networks and Local Linkages, McGill-Queen's University Press, Montreal and Kingston.

Nyman, G.S. (2015) 'University-business-government collaboration: from institutes to platforms and ecosystems', Triple Helix, Vol. 2, No. 1, p.2.

Mack, N., Woodsong, C., MacQueen, K.M., Guest, G. and Namey, E. (2005) Qualitative Research Methods: A Data Collectors Field Guide, Family Health International, Research Triangle Park, North Carolina.

Mota, R. and Scott, D. (2014) Educating for Innovation and Independent Learning, Elsevier, Oxford.

Rasmussen, E. and Wright, M. (2015) 'How can universities facilitate academic spin-offs? An entrepreneurial competency perspective', The Journal of Technology Transfer, Vol. 40, No. 5, pp.782-799.

Rauhvargers, A. (2011) 'Global university rankings and their impact', Leadership for WorldClass Universities Challenges for Developing Countries, June.

Regele, M.D. and Neck, H.M. (2012) 'The entrepreneurship education sub-ecosystem in the United States: opportunities to increase entrepreneurial activity', Journal of Business and Entrepreneurship, Vol. 23, No. 2, p.25.

Ries, E. (2011) The Lean Startup, Crown Business, New York.

Rolim, C., Serra, M. and Bastos, A.P.V. (2014) 'Changing Brazilian higher education institutions towards the third mission: the case of two Brazilian universities', EAIR 36th Annual Forum, Germany, August, pp.27-30.

Singer, S., Amorós, J.E. and Arreola, D.M. (2015) Global Entrepreneurship Monitor 2014 Global Report, Global Entrepreneurship Research Association, London Business School.

Spinosa, L., Schlemm, M. and Reis, R. (2015) 'Brazilian innovation ecosystems in perspective: some challenges for stakeholders', in REBRAE: Revista Brasileira de Estratégia, Vol. 8, No. 3, pp.386-400

Stangler, D. and Bell-Materson, J. (2015) 'Measuring and entrepreneurial ecosystem', Kauffman Foundation Research Series on City, Metro and Regional Entrepreneurship.

Tornatzky, L.G. and Rideout, E.C. (2014a) Innovation U2.0 Reinventing University Roles in a Knowledge Economy, Innovation-U.com. 
Tornatzky, L.G. and Rideout, E.C. (2014b) 'Stanford University', in Innovation U2.0 Reinventing University Roles in a Knowledge Economy, Louis G. Tornatzky (Publish.), North Carolina.

Tornatzky, L., Fuss, J. and Rideout, E. (2014) 'Stanford University', in Innovation U 2.0, Reinventing University Roles in a Knowledge Economy, Louis G. Tornatzky (Publish.), North Carolina.

USP (2015) USP em Números, Universidade de São Paulo [online] http://www.uspdigital.usp.br/ anuario/br/tabelas/PDF/2014/usp_em_numeros.pdf (accessed 10 January 2017).

Uvarov, A. and Perevodchikov, E. (2012) 'The entrepreneurial university in Russia: from idea to reality', Procedia Social and Behvioural Sciences, Vol. 52, pp.45-51.

Wong, P-K., Ho, Y. and Singh, A. (2007) 'Towards an 'entrepreneurial university' model to support knowledge-based economic development: the case of the national university of Singapor', World Development, Vol. 35, No. 6, pp.941-958.

Wong, P-K. and Wang, C. (2004) 'Entrepreneurial interest of university students in Singapore', Technovation, Vol. 24, No. 2, pp.163-172, DOI: 10.1016/S0166-4972(02)00016-0.

Zouain, D.M. and Plonski, G.A. (2015) 'Science and technology parks: laboratories of innovation for urban development-an approach from Brazil', Triple Helix, Vol. 2, No. 1, p.7. 